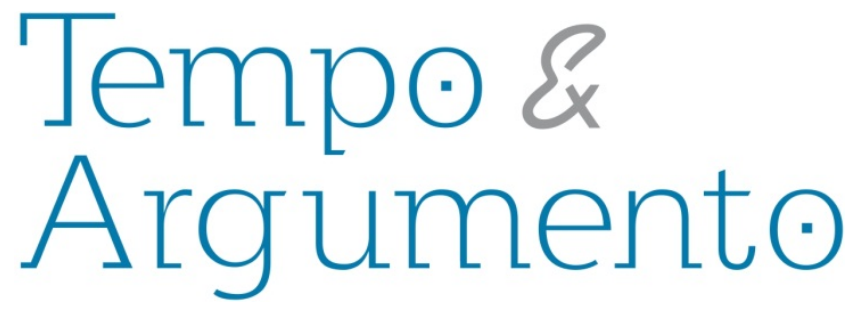

\title{
Rumo à Catástrofe
}

\section{Resenha da obra:}

ROUSSO, Henry. A última catástrofe: a história, o presente, o contemporâneo. Trad.

Fernando Coelho e Fabrício Coelho. Rio de Janeiro: FGV, 2016.

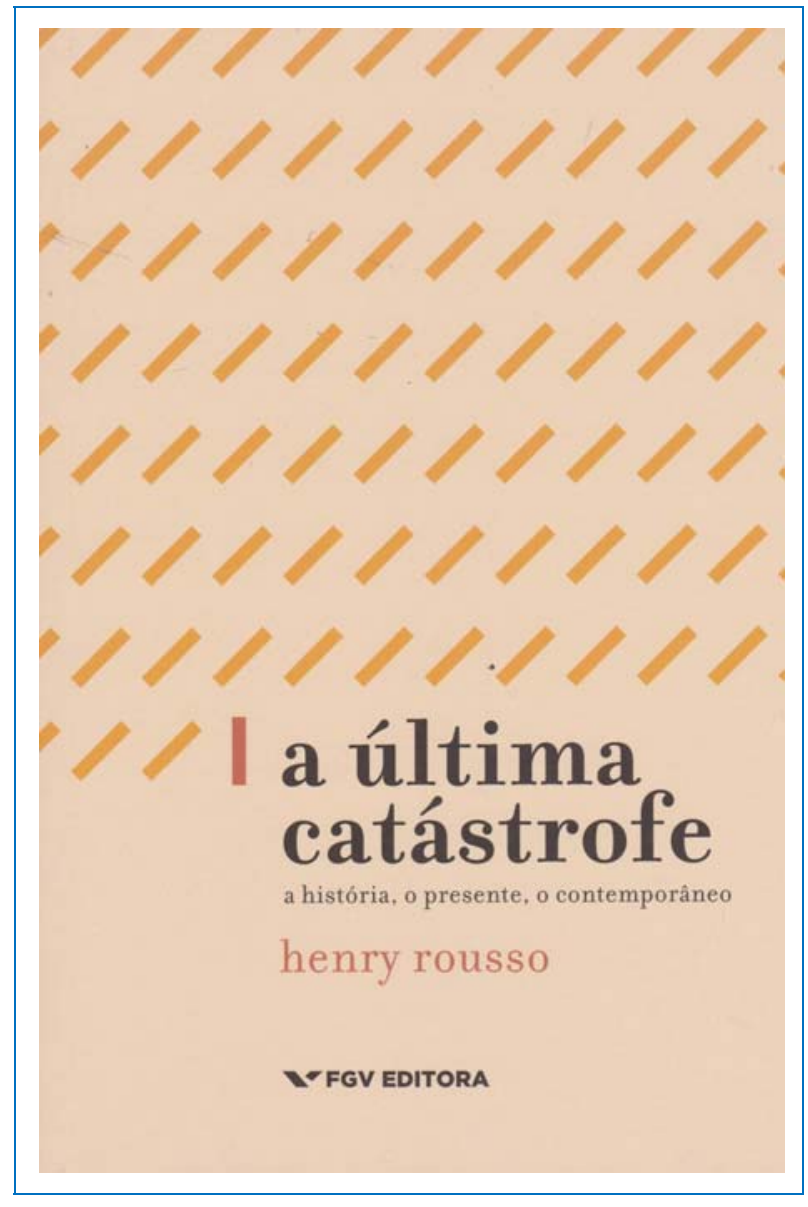

\section{Autor da resenha}

\section{Dilton Cândido Santos Maynard}

Doutor em História pela Universidade Federal de Pernambuco. Professor do Mestrado Profissional em Ensino de História da Universidade Federal de Sergipe, e do Programa de Pós-Graduação em História Comparada da Universidade Federal do Rio de Janeiro. Membro do Grupo de Estudos do Tempo Presente da Universidade Federal de Sergipe. Bolsista Produtividade CNPq. Brasil dilton@getempo.org

\section{Para citar esta resenha:}

ROUSSO, Henry. A última catástrofe: a história, o presente, o contemporâneo. Trad.

Fernando Coelho e Fabrício Coelho. Rio de Janeiro: FGV, 2016. Resenha de: MAYNARD, Dilton Cândido Santos. Rumo à Catastrofe. Revista Tempo e Argumento, Florianópolis, v. 9, n. 20, p. 333 - 338. jan./abr. 2017. 
A história do tempo presente está na moda. De uma abordagem comparada em curioso tom pejorativo ao jornalismo e à sociologia, nos últimos anos ela passou a receber tratamento atencioso no mercado editorial e obteve demonstrações de prestígio na Academia. Da rarefação passamos à oferta ampla. Este movimento, que levou a HTP da periferia para o cerne dos debates historiográficos, pôde ser observado no número crescente de congressos, workshops, simpósios temáticos, grupos de pesquisa e publicações dedicadas à rubrica.

Porém este avanço inspira cuidados. Como lembrou Robert Darnton ao tratar do Iluminismo, quando algo "está começando a ser tudo", pode findar sendo nada (DARNTON, 2005:18). É preciso, então, buscar uma definição mais acertada das fronteiras, dos procedimentos e das especificidades da história do tempo presente. É este o desafio assumido no livro A última catástrofe: a história, o presente, o contemporâneo, do historiador francês Henry Rousso, publicado no Brasil pela Editora da Fundação Getúlio Vargas em 2016.

Nos quatro e densos capítulos - além da introdução e da conclusão -, a obra originalmente publicada em francês com o título La dernière catastrophe : L'histoire, le présent, le contemporain (Paris, Gallimard, 2013) propõe questionamentos e apresenta respostas possíveis com desenvoltura e coragem. Com o objetivo de "retraçar a evolução, compreender os móbiles, explicar os paradigmas e os pressupostos dessa parte da disciplina histórica que passou, em algumas décadas, da margem ao centro" (18), Rousso toma a metáfora da catástrofe como "revolvimento" e "desenlace teatral"(28) para, no desenrolar dos ensaios, oferecer uma leitura que parece colocar ordem no caos de abordagens sobre a história do tempo presente.

Os ensaios escritos pelo pesquisador nascido no Cairo, em 1954, são distribuídos através dos capítulos: 1. A Contemporaneidade no passado (31-98), 2. A guerra e o tempo posterior (99-164), 3. A contemporaneidade no cerne da historicidade (165-218) e 4. O nosso tempo (219-280). Os dois primeiros ensaios percorrem a trajetória da história do tempo presente, enquanto nos seguintes, sobretudo no último, Rousso encara o desafio de pensar respostas aos problemas que levanta na obra. 
Assim, após demonstrar a persistência da ideia de uma história do tempo presente na longa duração, o autor evidencia uma forma "particular" de HTP a partir dos anos 1970. O olhar de Rousso percorre a historiografia produzida na Inglaterra, Alemanha e América do Norte, mas é na França, a sua base acadêmica - lembramos que ele é pesquisador do renomado Institut d'histoire du temps present, além de possuir atuação frequente no universo acadêmico dos EUA - o espaço de maior atenção, justamente por ver ali algumas das manifestações centrais ao desenvolvimento do campo.

De modo geral, na argumentação de Rousso, temos dois vetores importantes, dois “momentos inaugurais" fundamentais: a I Guerra Mundial - na qual emergem a testemunha, a busca por coleções e a figura do expert, e a II Guerra Mundial - que reforça a importância do passado recente enquanto objeto.

Mas se as duas guerras mundiais foram elementos fundamentais para uma mudança na prática e na percepção histórica, é nos anos 1950-1970, que a HTP amplia a sua inserção como disciplina e obtém considerável apoio da mídia. A ideia de acontecimento e "acontecimento-monstro", como chamou Pierre Nora (1976), ganha contornos mais evidentes com episódios como o caso dos reféns nas Olimpíadas de Munique (1972) ou a Guerra do Vietnã (1955-1975), eventos televisionados que ampliaram a demanda social por explicações "históricas". Um sintoma deste avanço pode ser percebido na ocupação pelos historiadores de importantes espaços midiáticos na Europa (Georges Duby foi, provavelmente, o caso mais emblemático).

Mas quais as fronteiras do presente? Onde ele começa? Para Henry Rousso, na última catástrofe. O autor nos lembra do anjo pintado por Paul Klee (1879-1940), o Angelus Novus (1920), o mesmo mencionado por Walter Benjamin (1892-1940) em suas Teses sobre o conceito de História, de 1940. Ali, na nona tese lê-se que "O anjo da história deve ter esse aspecto. Seu rosto está dirigido para o passado. Onde nós vemos uma cadeia de acontecimentos, ele vê uma catástrofe única, que acumula incansavelmente ruína sobre ruína e as dispersa a nossos pés" (BENJAMIN, 1994:226).

Portanto, são os historiadores a definir a última catástrofe. Tais eventos catastróficos exigem das gerações a reflexão e a consequente síntese da sua história 
recente, implicam em muitas vezes reposicionar elementos da memória, transformam as identidades e acabam por reordenar as interpretações do passado. E quais os eventos “inaugurais" possíveis? Anos emblemáticos como 1789, 1917, 1940 (ao menos para a França), 1945, 1989 e 2001?

Para além dos anos inaugurais, conforme o autor, a história contemporânea enquanto um conhecimento constituído a partir da mediação é caracterizada pelo peso dos eventos catastróficos, pela demanda social em torno do historiador, pelo quase inevitável envolvimento judicial e pela importância dada à memória e à testemunha. A propósito, a presença da testemunha é marca deste tipo de pesquisa e é necessário considerar os influxos da emergência da "testemunha que vê, a testemunha que fala, a testemunha que escreve, seja o próprio historiador, desempenha claramente um papel essencial, uma vez que é um mediador primário, para não dizer único" (282), como adverte Rousso.

Uma coisa importante é que o autor não apenas provoca questionamentos, mas demonstra coragem em respondê-los no decorrer das 341 páginas do livro. A obra nos convida a refletir sobre o ofício do historiador e suas tarefas no século 20 . Rousso aponta a relevância do debate sobre o problema fundamental da periodização. A proximidade com os eventos e os desdobramentos disto. Em que medida o historiador deve estar afastado? "A queda do Muro de Berlim ou os atentados de 11 de setembro podem por sua vez constituir fronteiras para um novo período contemporâneo? É... cedo demais para dizê-lo" (279). Não há resposta fácil quando se trabalha com história do tempo presente.

O livro demonstra que a ideia de contemporaneidade sofreu profunda evolução. Se “toda história é história contemporânea", como afirmou Benedetto Croce (1866-1952), Rousso adverte, no entanto, que: “Isso não significa, contudo, que existe uma concepção contínua e imutável através de vários milênios na maneira de escrever sobre o seu próprio tempo: as modalidades, os métodos, as finalidades de escrita da história mudaram consideravelmente de uma civilização para a outra" (281).

Mas, sim, toda história é contemporânea na medida em que "a história do passado encerrado que seria distinto, e até mesmo cortado em relação ao tempo presente, não 
tem sentido realmente" (41). Diferente de outros momentos, não se trata de obter o conhecimento a partir de uma ação da Providência ou de uma revelação, é importante considerar a história como conhecimento mediado como uma mudança crucial no sentido atribuído ao tempo presente.

Por sua vez, a ideia de memória é fundamental à história do tempo presente, pois ela descola a HTP do presentismo, da ideia de uma história imediata. A memória confere duração. Deste modo, Henry Rousso ressalta que se configura como um antídoto ao presentismo, não de um sintoma deste fenômeno. A desconstrução de uma leitura linear da história e a valorização das idas e vindas, da presença do passado no presente e do presente no passado exige o trabalho em duas frentes, como lembra o autor: "a da história e a da memória, a de um presente que não quer passar, a de um passado que volta para assombrar o presente, sendo a distinção entre as duas por vezes indisfarçável" (302).

A publicação da obra em português ocorre em momento bastante adequado, em tempos de ampla demanda por reflexões dos historiadores, dias de tensão nos rumos do Brasil, do Mundo, mas também em momento de duros questionamentos acerca do papel social do historiador, da sua necessidade nas salas de aula e da sua validade na orientação das políticas públicas. Neste aspecto, a obra contempla a situação de inúmeros intelectuais que, em diferentes países e contextos, foram chamados a colaborar em processos judiciais, foram interpelados pelas vítimas e pressionados pelos agressores.

Neste sentido, Henry Rousso nos lembra que "o historiador do presente mantém relações conflituosas com o poder, seja religioso, seja político" (282). Em tempos de Donald Trump acelerando o relógio do Armagedon na Casa Branca, Marine Le Pen tocando o tambor da xenofobia na França e quando, no Brasil, assistimos, atônitos, alguém democraticamente eleito ser afastado do cargo com votos dos que celebram eufóricos, cheios de ódio e preconceito, os piores momentos da ditadura e seus torturadores mais temidos, ler A Última Catástrofe é convite irrecusável. 
BENJAMIN, Walter. Sobre o conceito de História. Obras Escolhidas: Magia e técnica, arte e política. São Paulo: Brasiliense, 1985. v. I.p.222-234

DARNTON, Robert. Os dentes falsos de George Washington: um guia não convencional para o século XVIII. Trad. José Geraldo Couto. São Paulo: Companhia das Letras, 2005.

NORA, Pierre. O Retorno do Fato. in NORA, Pierre, LE GOFF. Novos Problemas. Rio de Janeiro: Francisco Alves, 1995.p.179-193

ROUSSO, Henry. A última catástrofe: a história, o presente, o contemporâneo. Trad. Fernando Coelho e Fabrício Coelho. Rio de Janeiro: FGV, 2016. 